\title{
Kafka y Bolaño: ¿Para una literatura menor?
}

\author{
Kafka and Bolaño: For a minor literature?
}

\section{Alexis Candia-Cáceres, Daniuska González González*}

Universidad de Playa Ancha (Centro de Estudios Avanzados), Viña del Mar, Chile

\section{Resumen}

Este artículo realiza un análisis comparativo entre la narrativa de Franz Kafka y la de Roberto Bolaño. Se busca establecer las convergencias y las divergencias que existen entre ambos autores. Para esto, se emplea una metodología basada en los aportes que Aldridge, Clements, Wellek, Warren y Chaitin han efectuado al desarrollo de la literatura comparada. El foco central del análisis está sustentado en las tres características de la literatura menor propuestas por Deleuze y Guattari. Se sostiene que Kafka y Bolaño construyen literaturas teratológicas que comparten dos características de la literatura menor y que difieren en otra. Ambos autores realizan usos desterritorializados de la lengua producto de las experiencias vitales que tienen en diversas ciudades occidentales $y$, además, efectúan articulaciones de lo individual en lo político, dado que sus proyectos escriturales le dan especial énfasis al tratamiento del poder. Sin embargo, Kafka y Bolaño tienen una marcada distancia en cuanto al carácter colectivo de sus producciones

ACC: Doctor en Literatura, e-mail: ivan.candia@upla.cl

DGG: Doctora en Humanidades, e-mail: daniuska.gonzalez@upla.cl 
literarias. Si bien este rasgo se puede reconocer en el autor de El castillo, tanto por el tratamiento de sus relatos como por la utilización de la letra K para designar a un protagonista colectivo, no sucede lo mismo con el autor de 2666, quien solo a una parte de sus narraciones le da ese cariz y a que el empleo de la consonante $B$ da cuenta de un protagonista particular. Asimismo, la investigación debate la idea de Deleuze y Guattarri en orden a asociar a Kafka y Bolaño con la falta de talento y la imposibilidad de realizar una literatura de "maestros".

Palabras claves: Franz Kafka. Roberto Bolaño. Literatura comparada. Literatura menor. Siglos XX-XXI.

\section{Abstract}

This research proposes a comparative analysis between the narrative of Franz Kafka and Roberto Bolaño. Specifically, the study was centered into establish both convergences and divergences between the two authors. The study used a methodology supported in the contributions made by several authors to the development of comparative literature (i.e., Aldridge, Clements, Wellek, Warren and Chaitin). This research focuses their interest in the three characteristics of minor literature proposed by Deleuze and Guattari. It is argued that Kafka and Bolaño perform a teratological literature that share two characteristics of minor literature, however they differ in other characteristic issue. Both authors make a deterritorialization use of language, which is a product of life experiences in various Western cities, and in addition, they have made an articulation of the individual in the immediate-political, because their writing projects give particular emphasis to the treatment of power. Nevertheless, Kafka and Bolaño have made a marked distance in terms of the collective character in their literary productions. While this feature can be recognized in the author of The castle, specially by the treatment of his stories as well as the use of the letter K to designate a collective protagonist, this is not the case with the author of 2666, who only gives to one part of their narratives that aspect, and the use of the consonant $B$ is employed to identify a particular protagonist. This research discusses the idea of Deleuze and Guattari in order to associate both Bolaño and Kafka, with the lack of talent and the impossibility of perform a literature of "masters".

Keywords: Franz Kafka. Roberto Bolaño. Comparative literature. Minor literature. XX-XXI century. 


\section{Introducción}

Franz Kafka y Roberto Bolaño tienen una serie de afinidades entre sí. Ambos son dueños de obras literarias excepcionales, en sus distintos idiomas - alemán y español, respectivamente -, que contribuyeron a abrir y profundizar los modos de representación y figuración de las letras occidentales. Muestran predilección por estéticas fragmentarias e inacabadas. Asumen la irrupción del mal y de lo extraño como temáticas hegemónicas en sus construcciones narrativas. Tuvieron una recepción crítica que mejoró sustancialmente tras sus muertes. Más allá de estos puntos en común, no se puede soslayar que existen, sin embargo, diferencias importantes entre Kafka y Bolaño: el tratamiento y los alcances del poder, el componente autobiográfico, la mayor presencia de elementos "mágicos" en los textos bolañanos ${ }^{1}$, entre otros.

Bajo esta perspectiva, intentar una aproximación comparativa entre Kafka y Bolaño no parece una ambición desproporcionada. Más aun cuando existen una serie de antecedentes complementarios que permiten establecer esa conexión. Bolaño manifestó, en diversas ocasiones, su admiración por el autor de La metamorfosis: "Kafka [...] es el mejor escritor de este siglo" (2004, p. 326); "La literatura de Kafka, la más esclarecedora y terrible (y también más humilde) del siglo XX" (2003, p. 43). Asimismo, es necesario establecer que existe proximidad de Bolaño hacia Kafka por cuanto compartieron la perseverancia de escribir a pesar de las enfermedades que afectaron su calidad de vida en sus últimos años. Así, Bolaño parece extraer de Kafka una lección a la hora de entender la importancia del viaje y la escritura:

1 Lejos de las definiciones tradicionales de lo mágico, Bolaño considera la "magia" como aquellos elementos fascinantes que rompen con la lógica consumista de las sociedades contemporáneas. Bolaño piensa que ante sociedades regidas por la oferta y la demanda, es necesario introducir una pieza que evite la enajenación a la que conduce el capitalismo. De ahí que emplee la magia para expandir la experiencia humana allende de los límites del mercado. Así, en 2666 responde a la pregunta ¿Y que es magia?: "Magia es épica y también es sexo, y bruma dionisiaca y juego" (BOLAÑO, 2006, p. 291). Estos elementos no aparecen con la misma fuerza en los textos kafkianos (CANDIA, 2010). 
Cuenta Cannetti en su libro sobre Kafka que el más grande escritor del siglo XX comprendió que los dados estaban tirados y que ya nada le separaba de la escritura el día que por primera vez escupió sangre. ¿Qué quiero decir cuando digo que ya nada le separaba de su escritura? [...] Supongo que quiero decir que Kafka comprendía que los viajes, el sexo y los libros son caminos que no llevan a ninguna parte, y que sin embargo son caminos por los que hay que internarse y perderse para volverse a encontrar o para encontrar algo, lo que sea, un libro, un gesto, un objeto perdido, para encontrar cualquier cosa, tal vez un método, con suerte: lo nuevo, lo que siempre ha estado allí (2003, p. 158).

Adicionalmente, es relevante considerar que Bolaño asimila y enfrenta la influencia de Kafka. Ciertamente, el hecho más significativo en esta dirección es que en El gaucho insufrible (2003) incluye un relato titulado "El policía de las ratas", que dialoga estrechamente con "Josefina la cantora o El pueblo de los ratones", en la medida que el escritor chileno arranca su relato desde el mismo espacio literario creado por el narrador checo, es decir, ambienta su historia en el pueblo de los ratones.

La crítica literaria ha reconocido, de manera parcial, las relaciones intertextuales que se producen entre ambos escritores. Tanto Ilinca Ilian como Wilfrido Corral han marcado esa relación. Para Corral la narrativa bolañana está bajo el influjo de ciertos autores canónicos europeos: “[...] decir que podría ser nuestro Joyce y Kafka" (2004, p. 36). En "Pierre Menard, autor de Bolaño" Fabián Saberón formula una interesante conexión entre ambos autores, cuando afirma que Bolaño - al igual que Kafka - mantiene una apasionada relación con la literatura (2006) y luego agrega, citando a Kafka: “Mi manera de vivir está organizada únicamente en función de escribir', le dijo Kafka a Felice Bauer². Bolaño le debe a Borges lo que Borges le debe a Kafka: la afirmación absoluta y pasional de que todo es literatura o de que todo puede convertirse en literatura" (SABERÓN, 2006). Carlos Villacorta González realiza, por su parte, una aproximación entre "Josefina la cantora o El pueblo de los ratones" y "El policía de las ratas" a partir del rol que

22666 parece evidenciar un nuevo reconocimiento a Kafka. Allí la esposa de Archimboldi - uno de los protagonistas de texto - toma su apellido, aparentemente, de la novia de Kafka: Ingeborg Bauer. 
ambos escritores le asignan a la figura del artista y el papel que éste cumple en la comunidad:

A diferencia de la historia de Kafka donde se busca tachar el nexo que une al artista y su público, Bolaño enfatiza el problema del arte de manera diferente. El arte no está relacionado con el canto ni con la (no) performance, sino con la capacidad de la comunidad de crear una simulación de una estructura de sentimientos entre los sujetos, a saber entre el artista y el público (2013, p. 149-150).

Como es posible apreciar, aún son parciales los intentos por realizar una lectura comparativa entre Kafka y Bolaño. De esta forma, la novedad que implica realizar este ejercicio amerita efectuar un trabajo con ambos autores. Para realizar este estudio asumimos una postura heterodoxa. Así, se emplea una metodología que combina las visiones de Aldridge, Clements, Wellek y Warren con la de Chaitin:

Aldridge y Clements le dan relevancia a la comparación y la reconciliación como sus ejes centrales, hasta el punto que buscan la igualdad entre las unidades, la que se sustenta en la totalidad del objeto - la literatura universal o europea, por ejemplo - y que lleva a Curtius a afirmar que la literatura occidental forma una comunidad histórica y una unidad fundamental. En este contexto, Wellek y Warren llevan el cosmopolitismo hasta el paroxismo. No sólo abogan por la comprensión de la literatura como una totalidad, sino que demandan la supresión de la autonomía local. Asimismo, consideran las literaturas nacionales como simples contribuciones a la literatura universal. Ciertamente, tal percepción de la literatura elimina cualquier tipo de diferencia y otredad en el método de la literatura comparada [...] Ante ese modelo de la literatura comparada, Gilbert Chaitin opondrá una literatura diferencial que no sólo cuestiona la unidad de esa literatura general, sino que modificó substantivamente su método de análisis, remplazando la búsqueda de la homogeneidad por la persecución de la otredad. [...] Chaitin propone, en suma, un enfoque tendiente a dar un giro a la visión tradicional de la literatura comparada, concentrada, tradicionalmente, en la búsqueda de semejanzas y en la construcción de generalidades, a fin de establecer las diferencias y, especialmente, las otredades que existen entre las literaturas locales (CANDIA, 2015, p. 14). 
Para estudiar la producción de ambos autores se emplearán los aportes que Deleuze y Guattari realizan acerca de la noción de literatura menor, la que es entendida no como: "la literatura de un idioma menor, sino la literatura que una minoría hace dentro de una lengua mayor" (2002, p. 26). De esta forma, la literatura menor ofrece la idea de memoria como contra-poder, debido a que plantea la posibilidad de una identidad que queda absorbida por "un pueblo que falta" (DELEUZE, 1996, p. 9). Para Deleuze, la literatura, como otras manifestaciones artísticas, supera las barreras de lo meramente artístico en la medida que cada impresión y vivencia personal transformada en ficción literaria intentará trazar una ruta: "No escribimos con los recuerdos propios, salvo que pretendamos convertirlos en el origen o el destino colectivos de un pueblo venidero todavía sepultado bajo sus traiciones y renuncias" (DELEUZE, 1996, p. 9). Por ello se dice que la literatura instala una política en el lenguaje contra la normalidad que instituye y supone la lengua mayor: "No hay, pues, dos tipos de lenguas, sino dos tratamientos posibles de una misma lengua" (DELEUZE; GUATTARI, 2004, p. 106).

\section{Literaturas teratológicas}

“Josefina la cantora o El pueblo de los ratones" y “El policía de las ratas" comparten la predilección por abordar acciones o individuos que no se ajustan al patrón común de una sociedad y que, por consiguiente, caen en el terreno de la anomalía y/o de lo extraño. Así, mientras el texto de Kafka aborda la historia de una rata que canta a pesar de su imposibilidad fisiológica $\mathrm{y}$, sobre todo, del desinterés de su pueblo: "y esto prueba su valor, ya que en general nuestra raza no aprecia la música. La quietud es nuestra música predilecta" (1981, p. 89); el cuento de Bolaño da cuenta de cómo Pepe el Tira - sobrino de Josefina - se enfrenta a un criminal que viola una de las normas de su especie: "Las ratas no matan otras ratas" (2003, p. 84). Tras enfrentar a Héctor - el asesino de ratas - Pepe el Tira tiene un sueño que, en alguna medida, explica la relación de estos hechos con las propuestas literarias de ambos autores: 
un virus desconocido ha infectado a sus pueblos. Esta manifestación onírica es interesante porque permite comprender cómo esas anomalías se extienden por las producciones textuales de Kafka y Bolaño, generando, en definitiva, un cuerpo textual que se ve sometido a los efectos de la enfermedad. De esta forma, se puede trazar un paralelo entre sus concepciones literarias y la Teratología, es decir, la ciencia que estudia las malformaciones y las anomalías en distintas clases de organismos vivos.

La literatura teratológica sirve, entonces, como un paraguas que permite comprender el diálogo que se produce entre Kafka y Bolaño. Para profundizar en sus convergencias y sus divergencias se utilizarán los tres rasgos centrales propuestos sobre la literatura menor por Deleuze y Guattari.

\section{Desterritorialización de la lengua}

La historia vital de Franz Kafka es capital para comprender el primer rasgo de la literatura menor. Principalmente por la hibridez cultural que experimentó en su trayecto vital: Kafka es un escritor checo, de origen judío, que escribió en alemán. Nacido en Praga en una familia de judíos asquenazíes, asimiló la herencia lingüística checa por parte de su padre y la alemana por parte de su madre. Sin embargo, es claro que, en términos literarios, la herencia germana resulta mucho más pesada en Kafka, quien termina escribiendo la inmensa mayoría de su producción literaria en alemán - salvo algunas cartas escritas en checo $-\mathrm{y}$, en especial, su producción narrativa.

A partir de esta condición lingüística nómade de Kafka, los teóricos franceses proponen que el autor de El proceso experimenta un proceso de desterritorialización de la lengua: "Kafka define de esta manera el callejón sin salida que impide a los judíos el acceso a la escritura y que hace de su literatura algo imposible: imposibilidad de no escribir, imposibilidad de escribir en alemán, imposibilidad de escribir de cualquier manera" (DELEUZE; GUATTARI, 2002, p. 26). Precisamente, la noción de imposibilidad pone a Kafka, en la perspectiva de Deleuze y 
Guattari, en un callejón sin salida que impide el acceso a la escritura: "Imposibilidad de no escribir, porque la consciencia nacional, insegura y oprimida, pasa necesariamente por la literatura" (2002, p. 26). Kafka. Para una literatura menor da cuenta del proceso de invención que efectúa el escritor checo a fin de generar una producción literaria que desafía las concepciones culturales y lingüísticas que enfrenta en la Praga de su época:

La imposibilidad de escribir en otro idioma que no sea el alemán es para los judíos de Praga el sentimiento de una distancia irreductible con la territorialidad primitiva checa. Y la imposibilidad de escribir en alemán constituye la desterritorialización de la población alemana misma, minoría opresora que habla un idioma ajeno a las masas, como un "lenguaje de papel" o artificial: con mayor razón los judíos, quienes forman parte de esta minoría al mismo tiempo que son excluidos de ella como "gitanos que robaron al niño alemán en la cuna". En fin, el alemán de Praga es una lengua desterritorializada, adecuada para extraños usos menores (2002, p. 26-27).

Deleuze y Guattari sostienen que el proceso de desterritorialización que experimenta Kafka es replicable en el caso de otros escritores. Así, por ejemplo, Joyce y Beckett experimentan un trance similar al de Kafka, escritores irlandeses que están inmersos en condiciones extraordinarias de una literatura menor (DELEUZE; GUATTARI, 2002). En este mismo grupo podemos situar, también, a Sacher-Masoch, quien hace una literatura menor, "que es su misma vida, una literatura política de las minorías" (2002, p. 102). El análisis que Deleuze y Guattari efectúan sobre esta triada de autores es relevante porque explicitan que la noción de literatura menor se refiere, además, a la posibilidad de hacer en su propia lengua una literatura menor y tanto más política por ello mismo, tal como plantean sobre Sacher-Masoch; "encuentra medios de expresión según su genio, en un uso arcaico, simbolista y estereotipado del lenguaje, o por el contrario, en una sobriedad que le arranca a la lengua una pura queja y una provocación" (2002, p. 102). A lo anterior, se suma el hecho de que ambos autores no piensan en este fenómeno en términos 
estrictamente artísticos sino que se puede extender a lo que experimentan determinadas comunidades, tales como lo que enfrentan los afroamericanos en Estados Unidos.

¿Ocurre lo mismo con Bolaño? Veamos. Uno de los aspectos de la irrupción de Bolaño que llamó inmediatamente la atención en la literatura hispanoamericana, fue su condición de escritor trashumante, extranjero, desterritorializado. Bolaño no podía ser situado como parte de la literatura chilena ni mexicana ni española, erigiéndose, en esta línea, en una especie de paria, tal como el mismo reconoce en su "Discurso de Caracas":

pues a mí lo mismo me da que digan que soy chileno, aunque algunos colegas chilenos prefieran verme como mexicano, o que digan que soy mexicano, aunque algunos colegas mexicanos prefieren considerarme español, o, ya de plano, desaparecido en combate, e incluso lo mismo me da que me consideren español, aunque algunos colegas españoles pongan el grito en el cielo y a partir de ahora digan que soy venezolano (2004, p. 36).

A partir de esta cita, es posible sostener que Bolaño tuvo un proceso formativo nómade. Dividió su periplo vital entre Chile, México y España y, en este sentido, es clave considerar que las tres naciones ejercieron una influencia decisiva en su formación como escritor. Así, Bolaño sostiene: "Chile es mi infancia y México mi adolescencia y mi primera juventud" (2001, p. 46). Siguiendo esa lógica, es dable afirmar que España es su adultez. Esta última afirmación no es menor porque, salvo la breve etapa de producción lírica mexicana, compuesta por un libro de poesía y un puñado de poemas publicados en revistas y ediciones comunitarias, Bolaño construye la mayor parte de su producción literaria en España, es decir, desde la metrópoli integra en su escritura las más variadas manifestaciones del español de Latinoamérica. Leonidas Morales sostiene, en este sentido, respecto de la obra de Bolaño que: "[...] dentro de un amplio espectro cultural de hablas (el de la lengua española) opta por domicilios transitorios, o mejor, en tránsito. Enunciación híbrida sin duda. No parece haber en la tradición narrativa chilena (novela y cuento) nada comparable desde este 
punto de vista" (2008, p. 50). No por nada Los detectives salvajes fueron calificados como la mejor novela mexicana desde la publicación de $L a$ región más transparente (1958) de Carlos Fuentes. Así, Bolaño incorpora diferentes variantes del español latinoamericano pero, por cierto, pasándolo bajo el cedazo del español de la "madre patria".

\section{Articulación de lo individual en lo inmediato-político}

En una carta escrita a Max Brod en 1912 Kafka define que "El arte es un espejo que se adelanta, como a veces los relojes" (DELEUZE; GUATTARI, 2002, p. 46). Esta sentencia es relevante porque constituye una reflexión metacrítica que da cuenta de un rasgo central de la obra kafkiana: su carácter profético. Así, por ejemplo, se podría establecer que mientras El proceso anticipa el burocratismo soviético; El castillo adelanta el fascismo y América el capitalismo avanzado (ABRAHAM, 2011). Más allá de la proyección específica de cada uno de estos textos, interesa fijar la atención en cómo las novelas de Kafka advierten la relación venidera entre el sujeto y la política. Si la política es en una de sus acepciones tradicionales la lucha por el poder, es claro que el autor checo vaticina la manera en que el individuo enfrenta instituciones que, en la mirada de Max Weber en Economía y sociedad, procuran imponer su propia voluntad en una acción comunitaria inclusive contra la oposición de los demás miembros. La imposición de la voluntad puede conducir a un caso especial del ejercicio del poder: la dominación, esto es, un estado de cosas por el cual una voluntad manifiesta "mandato" del dominador o de los dominadores, influye sobre los actos del otro (WEBER, 2014). Así, las novelas de Kafka anticipan la relación que los individuos establecen con un organismo que detenta y ejerce el poder en contra de la ciudadanía, lo que anticipa el surgimiento de los estados totalitarios de mediados y fines del siglo XX.

En su diario Kafka anota una reflexión que contribuye a entender su relación con la política, la que, por cierto, en alguna medida motiva la segunda característica que Deleuze y Guattari formulan acerca de la literatura menor: 
Aunque a menudo el asunto concreto sea examinado a fondo y con calma, no por ello se llega a los límites donde entra en conexión con asuntos afines: mucho más fácil es alcanzar el límite de la política, e incluso se aspira a ver ese límite antes de que se presente, y a descubrir por doquier estos límites restringidos [...] Aquello que, dentro de las grandes literaturas, se produce en la parte más baja y constituye un sótano del cual se podría prescindir en el edificio, ocurre aquí a plena luz; lo que allí provoca una concurrencia esporádica de opiniones, aquí plantea nada menos que la decisión sobre la vida y la muerte de todos (2002, p. 27-28).

A partir de este desdibujamiento de los límites de la política Kafka. Para una literatura menor plantea que la segunda característica de la literatura menor es que en ella todo es político. Así, por ejemplo, situaciones que aparentemente afectan a individuos como, por ejemplo, la oposición de padres a hijos son, en la perspectiva kafkiana, un programa político:

En las "grandes" literaturas, por el contrario, el problema individual (familiar, conyugal, etcétera) tiende a unirse con otros problemas no menos individuales, dejando el medio social como una especie de ambiente o de trasfondo [...] La literatura menor es completamente diferente: su espacio reducido hace que cada problema individual se conecte de inmediato con la política (2002, p. 27).

Con el objetivo de comprender este punto, abordaremos El proceso y El castillo de Kafka en relación a Estrella distante, Nocturno de Chile y 2666 de Bolaño.

Frente a los textos de Kafka existen, al menos, dos interpretaciones generales posibles. Uno. Max Brod lee estas novelas a partir del vínculo que ambas establecen con la divinidad. Así, para el amigo de Kafka, los libros dan cuenta del vínculo del individuo con "la gracia', la conducción divina del destino humano, la vigencia del azar, misteriosos designios, favores y perjuicios, lo no merecido e inalcanzable, el 'no liquet', y el don en la vida de todos"' (KAFKA, 1977, p. 324). Dos. Deleuze y Guattari optan, más bien, por una mirada realista y social "Y más vale hablar de los problemas de la literatura menor, de la situación de un judío en Praga, de Estados Unidos, de la burocracia y de los 
grandes procesos, que de un Dios ausente" (2002, p. 72). Nos inclinamos por la apreciación de los teóricos franceses, dado que no solo nos parece más pertinente para la propuesta literaria de Kafka, sino porque esta permite trazar, inmediatamente, un puente con Bolaño, autor que elude cualquier clase de conexión con la divinidad y que desarrolla un proyecto literario profundamente antropocéntrico.

Considerando lo anterior, es factible sostener que varios libros de Kafka y Bolaño abordan el dominio y la coacción que ejerce el poder sobre el individuo. De esta forma, El proceso relata la extraña causa judicial a la que es sometido el apoderado de Banco Josef K o simplemente K, cuya acusación nunca es conocida por el lector y, en consecuencia, tampoco su inocencia o su culpabilidad. Así, resulta interesante consignar que el narrador solo entrega atisbos de los engranajes del tribunal, tales como el papel que desempeñan los guardianes o los abogados pero que, en definitiva, son incapaces de explicar su dinámica interna. Con todo, se trata de un tribunal que se mueve sobre el estado de derecho. Es más, no hay posibilidad de alcanzar la inocencia sino solo de lograr una absolución real, una absolución aparente y el aplazamiento, es decir, el tribunal asume que todos son culpables. El Castillo cuenta el viaje de $\mathrm{K}$, un agrimensor, a un condado para prestar servicios al conde Westwest. K es llamado para trabajar para el castillo pero una serie de trabas burocráticas implican que llegue a realizar un trabajo innecesario. De esta manera, $\mathrm{K}$ inicia una serie de tratativas destinadas a lograr que se reconozca su posición. Aunque la novela no fue acabada por Kafka, sabemos por el epílogo de Brod que K no logra su cometido y que solo tras su muerte por inanición es reconocido su derecho a vivir y trabajar en las fronteras del condado.

¿Qué hay detrás de estos relatos? ¿Solo el conflicto entre un individuo y diferentes instituciones? Hay algo más, claro está. Ambas novelas tienen un potente cariz político en cuanto abordan la fuerza que el poder ejerce sobre el sujeto. Si El proceso narra la pugna entre $\mathrm{K}$ contra un misterioso tribunal, El castillo plasma el conflicto entre K con la fuerza política y burocrática. De allí que K sostenga "Poner en orden mis asuntos con las autoridades es mi mayor deseo, en realidad el único" (1977, p. 174). Ambos textos operan frente a un poder 
incomprensible, incuestionable y severo que, sin embargo, los protagonistas intentan resistir.

¿Sucede algo similar en la narrativa de Bolaño? Claro que sí. El conflicto del sujeto contra el poder se aprecia, por ejemplo, en "La parte de los crímenes" de 2666. Allí nos encontramos frente a una entidad organizada para violentar el cuerpo de centenares de mujeres que son torturadas, ultrajadas y asesinadas sin mayores consecuencias sobre los presuntos culpables, es decir, estamos frente a la presencia de una red que genera un círculo de horror protegido, a su vez, por un circuito de inmunidad. Al igual que Kafka, Bolaño nunca devela la identidad, los motivos, el sentido del ejercicio del poder. Solo conocemos, al igual como en El proceso, sus brutales resultados:

Pero las manos de uno de los señores se posaban ya en la garganta de $\mathrm{K}$, mientras el otro le hundía profundamente el cuchillo y lo hacía girar dos veces. Con los ojos vidriosos, $\mathrm{K}$ vio aún cómo los señores, muy cerca de su cara, mejilla contra mejilla, observaban la decisión. “¡Como un perro!", dijo, era como si la vergüenza hubiese de sobrevivirle (KAFKA, 1979 , p. 234).

La muerta tenía diez años, aproximadamente. Su estatura era de un metro y veintisiete centímetros. Llevaba zapatillas de plástico transparente, atadas con una hebilla de metal. Tenía el pelo castaño, más claro en la parte que le cubría la frente, como si lo llevara teñido. En el cuerpo se apreciaron ocho heridas de cuchillo, tres a la altura del corazón. Uno de los policías se puso a llorar cuando la vio (BOLAÑO, 2006, p. 627).

A diferencia de Kafka, Bolaño aborda, también, un poder visibilizado que consuma lo que Kafka anuncia en la primera parte del siglo $\mathrm{XX}$, esto es, el conflicto del sujeto con los estados totalitarios: "La parte de Archimboldi" de 2666 trata el horror de la Alemania nazi y Estrella distante y Nocturno de Chile dan cuenta de la brutal aplicación del poder en el Chile de Augusto Pinochet. Nocturno de Chile aborda, en este sentido, el proceso de aprendizaje de Pinochet, quien desea asimilar las nociones fundamentales del marxismo para saber hasta dónde necesita llegar para "neutralizar" una potencial amenaza. Estrella distante constituye, en tanto, la puesta en escena de una serie de acciones que 
responden a una estrategia sistemática de destrucción de los opositores del régimen. El "arte" de Carlos Wieder es el mejor ejemplo de lo anterior:

Según Muñoz Cano, en algunas de las fotos reconoció a la hermanas Garmendia y a otros desaparecidos. La mayoría eran mujeres. El escenario de las fotos casi no variaba de una a otra por lo que deduce es el mismo lugar. Las mujeres parecen maniquíes, en algunos casos maniquíes desmembrados, destrozados, aunque Muñoz Cano no descarta que en un treinta por ciento de los casos estuvieran vivas en el momento de hacer las instantáneas. Las fotos, en general, [...] son de mala calidad aunque la impresión que provocan en quienes las contemplan en vivísima. El orden en que están expuestas no es casual: siguen una línea, una argumentación, una historia (cronológica, espiritual...), un plan. Las que están pegadas en el cielorraso son semejantes [...] al infierno, pero un infierno vacío. Las que están pegadas (con chinchetas) en las cuatro esquinas semejan una epifanía. Una epifanía de la locura (BOLAÑO, 1996, p. 97).

En síntesis, ya se trate de un poder visible o invisible tanto Bolaño como Kafka revelan las máquinas del poder de la sociedad occidental.

\section{Dispositivo colectivo de enunciación}

Kafka. Para una literatura menor evidencia, en distintos momentos, la admiración que el autor de El proceso siente por Goethe, admiración que, por cierto, detona diversas preguntas en Deleuze y Guattari, como, por ejemplo, la cuestión de los motivos que explican esa apreciación: “ies en tanto 'maestro' o más bien en tanto autor del pacto diabólico de Fausto, que provoca el destino de Margarita?" (2002, p. 47). Los teóricos franceses tienden a considerar que la respuesta pasa, más bien, por la segunda apreciación, es decir, por el tratamiento del mal, sobre todo, al considerar que el propio Kafka afirmó que la creación literaria es "un salario por el servicio del diablo" (DELEUZE; GUATTARI, 2002, p. 47). Ahora bien, nosotros 
consideramos que la condición de "maestro" es un factor que explica complementariamente la relación de ambos autores.

Antes de profundizar en este aspecto del análisis, es relevante considerar la tercera característica de la literatura menor, la que considera que todo adquiere un valor:

En efecto, precisamente porque es una literatura menor no abunda el talento, por eso no se dan las condiciones para una enunciación individualizada, que sería la enunciación de tal o cual "maestro", y que por lo tanto podría estar separada de la enunciación colectiva. Y así esta situación de escasez de talento resulta de hecho benéfica; y permite la creación de algo diferente a una literatura de maestros: lo que el escritor dice totalmente solo se vuelve una acción colectiva, y lo que dice o hace es necesariamente político, incluso si los otros no están de acuerdo (DELEUZE; GUATTARI, 2002, p. 28).

La propuesta de Deleuze y Guattari nos genera una reacción encontrada. No solo a la hora de analizar la obra de Bolaño sino también la de Kafka. Desglosémosla. Concordamos con ambos autores en que en Kafka hay un valor colectivo. Asimismo, lo ejemplifican muy bien aludiendo al deseo de renunciar al principio del narrador a través de: a) La utilización de la letra $\mathrm{K}$ y no de un nombre propio para designar al protagonista de El castillo. b) La desaparición de Josefina la cantora hacia el final del relato representa la "renuncia al ejercicio individual de su canto para fundirse con la enunciación colectiva de la "innumerable multitud de héroes de [su] pueblo" (DELEUZE; GUATTARI, 2002, p. 29). Bolaño retoma en parte estos rasgos en su producción narrativa: a) La continuidad de "El policía de las ratas" con el mencionado cuento de Kafka al subrayar que el pueblo trabaja como un todo: "mi pueblo cava sin cesar, túneles que sirven para acceder a otras fuentes alimenticias o que sirven únicamente para escapar o para comunicar laberintos que [...] forman parte del entramado en el que mi pueblo se mueve y sobrevive" (2003, p. 55). A ello, hay que agregar que en la definición de su concepción literaria Bolaño confiere especial relevancia al factor colectivo: 
Todo lo que he escrito es una carta de amor o de despedida a mi propia generación, los que nacimos en la década del cincuenta y los que escogimos en un momento dado el ejercicio de la milicia, en este caso sería más correcto decir la militancia, y entregamos lo poco que teníamos, lo mucho que teníamos, que era nuestra juventud, a una causa que creímos la más generosa de las causas del mundo y que en cierta forma lo es, pero que en realidad no lo era (BOLAÑO, 2004, p. 36).

En Amuleto Bolaño deja en claro este valor colectivo al optar por narrar el crimen atroz que experimenta una generación de jóvenes latinoamericanos, inmolados en las "guerras floridas latinoamericanas" de las décadas de 1960 y 1970: "Y aunque el canto que escuché hablaba de la guerra, de las hazañas heroicas de una generación entera de jóvenes latinoamericanos sacrificados, yo supe que por encima de todo hablaba del valor y de los espejos, del deseo y del placer. Y ese canto es nuestro Amuleto" (BOLAÑO, 1999, p. 154).

La utilización de la letra B, empleada por Bolaño en diversos cuentos de Llamadas telefónicas y Putas asesinas, tiene un sentido distinto respecto del empleo de la letra $\mathrm{K}$ en los textos kafkianos. Aunque Bolaño le hace un reconocimiento a Kafka, le da un sentido menos colectivo al empleo de la letra que el autor de América: "La letra $\mathrm{K}$ ya no designa un narrador, ni un personaje, sino un dispositivo tanto más maquínico, un agente tanto más colectivo cuanto que es sólo un individuo el que se encuentra conectado a todo eso en su soledad" (DELEUZE; GUATTARI, 2002, p. 29). En síntesis, la letra $\mathrm{K}$ tiene una función general que se multiplica en sí misma y que no deja de segmentarse (DELEUZE; GUATTARI, 2002). No sucede lo mismo con los relatos bolañanos. Principalmente porque, lejos de la función colectiva que le otorga Kafka y que se aprecia al considerar que K designa a varios personajes (banquero, agrimensor, entre otros), Bolaño más bien emplea la consonante como parte de una estrategia autoficcional que, al igual que las nomenclaturas Arturo. B o Arturo Belano, tiende a plasmar diversos episodios de la vida del propio autor. De allí que las historias de B coincidan o se adecuen a la historia de Bolaño. Historias sobre conflictos literarios, amorosos 
o parentales ocupan un rol central en los textos protagonizados por B y, en consecuencia, se alejan de sus similares kafkianos.

Ahora bien, respecto de la propuesta de Deleuze y Guattari en este punto tenemos un reparo. Asociar la literatura de Kafka con ausencia de talento nos parece, por lo menos, erróneo. Más aun al considerar que se trata de una de las propuestas más sólidas de la literatura del siglo XX. Lo mismo sucede con Bolaño en el marco de la literatura latinoamericana de fines del siglo XX e inicios del siglo XXI. No creemos que Kafka y Bolaño no desarrollen la enunciación de tal o cual "maestro" por carencia de habilidades sino porque, en línea planteada por Harold Bloom, están allí para enfrentar la angustia de las influencias, desafiar a la tradición, subsumir al canon y generar, en definitiva, una obra propia. Deleuze y Guattari determinan que el maestro de Kafka es Goethe, el escritor más relevante de la literatura escrita en alemán. El gran maestro de Bolaño es Borges, el mejor narrador latinoamericano. Kafka y Bolaño enfrentan a sus maestros para generar una obra innovadora y revolucionaria. De allí que sus propuestas narrativas se adelanten - como señalaba el propio Kafka - a su tiempo, conciten el futuro, abran caminos y, sobre todo, bailen en la cuerda floja (DELEUZE; GUATTARI, 2002). En suma, ambos autores desarrollan una apuesta literaria que apunta, tal como plantean Deleuze y Guattari, a: "Escribir como un perro que escarba su hoyo, una rata que hace su madriguera. Para eso: encontrar su propio punto de subdesarrollo, su propia jerga, su propio tercer mundo, su propio desierto" (2002, p. 30).

\section{Consideraciones finales}

Franz Kafka y Roberto Bolaño desarrollan literaturas teratológicas que estudian y relatan - tal como muestra el significado etimológico de la palabra - la historia de los monstruos. Ambos autores se hacen cargo de explorar las anomalías de diversas comunidades y los desafíos que los sujetos les imponen a éstas y viceversa. 
Amparados en una metodología que persigue establecer las convergencias y las divergencias entre ambos autores, sobre la base de los aportes teóricos de Deleuze y Guattari, pudimos establecer que Kafka y Bolaño mantienen un interesante diálogo que está signado por una serie de afinidades y de rechazos. Mientras las afinidades pasan por la desterritorialización de la lengua y la articulación de lo individual en lo inmediato-político, las distancias pasan, sobre todo, por la consideración de que sus producciones literarias tienen de manera absoluta un valor colectivo. Si bien este rasgo es patente en Kafka no sucede lo mismo con Bolaño. De hecho Bolaño hace girar el uso de la consonante $B$ hacia una posición más individual de lo que Kafka hace con la letra análoga K. Asimismo, manifestamos nuestra diferencia con los autores de Mil mesetas respecto de que la obra de Kafka - pensada desde la literatura menor - carece de talento. Ni para Kafka ni para Bolaño es posible aplicar esta visión. Mucho más aún al considerar que ambos dialogan con "maestros" relevantes de las letras occidentales no para imitarlos sino para subsumir sus aportes y generar propuestas propias.

A pesar de las contribuciones de este artículo, es evidente que quedan una serie de temas pendientes que no fue posible abordar. Es imprescindible ahondar en los alcances del trabajo que ambos hacen en el marco de la literatura teratológica, en especial, en cuanto al estudio y la representación de las temáticas del mal y de lo extraño. Asimismo, es necesario profundizar el eslabón que enlaza con mayor intensidad el vínculo entre ambos escritores: Borges. Queda pendiente, también, la exploración del rizoma como mecanismo de construcción narrativa de los mundos literarios de ambos autores, el movimiento ilógico de las acciones de los personajes, la voluntad y/o la condición azarosa que determinó la publicación de piezas inacabadas.

Cabe consignar, en definitiva, que Bolaño y Kafka son dueños de máquinas literarias poderosas que seguirán desafiando el transcurso del tiempo, tiempo que, con seguridad, constituye el mejor juez de la calidad de la literatura. 


\section{Referencias}

ABRAHAM, T. La máquina Deleuze. Buenos Aires: Sudamericana, 2011.

BOLAÑO, R. Estrella distante. Barcelona: Anagrama, 1996.

BOLAÑO, R. Amuleto. Barcelona: Anagrama, 1999.

BOLAÑO, R. Putas asesinas. Barcelona: Anagrama, 2001.

BOLAÑO, R. El gaucho insufrible. Barcelona: Anagrama, 2003.

BOLAÑO, R. Entre paréntesis. Barcelona: Anagrama, 2004.

BOLAÑO, R. 2666. Barcelona: Anagrama, 2006.

CANDIA-CÁCERES, A. Todos los males el mal. La 'estética de la aniquilación' en la narrativa de Roberto Bolaño. Revista Chilena de Literatura, n. 76, p. 43-70, 2010.

CANDIA-CÁCERES, A. Irradiaciones y difuminaciones de la brutalidad en $\mathrm{La}$ condesa sangrienta y 2666. Aisthesis, n. 57, p. 11-29, 2015.

CORRAL, W. Lo que sobrevivirá del segundo boom Bolaño, el bolañismo. Revista Quimera, n. 241, p. 32-37, mar. 2004.

DELEUZE, G. Crítica y clínica. Barcelona: Anagrama, 1996.

DELEUZE, G; GUATTARI, F. Kafka. Para una literatura menor. Madrid: Editora Nacional, 2002.

DELEUZE, G; GUATTARI, F. Mil Mesetas. Capitalismo y Esquizofrenia. Valencia: Pre-textos, 2004.

KAFKA, F. El Castillo. Buenos Aires: Losada, 1977.

KAFKA, F. El proceso. Barcelona: Lumen, 1979.

KAFKA, F. La metamorfosis y otros relatos. Santiago: Andrés Bello, 1981.

MORALES, L. Roberto Bolaño. Las lágrimas son el lugar de la esperanza. Atenea, n. 497, p. 51-77, 2008. 
CANDIA-CÁCERES, A.; GONZÁLEZ, D. G.

SABERÓN, F. Pierre Menard, autor de Bolaño. Espéculo. Revista de estudios literarios, n. 33, 2006. Disponible en: <https://pendientedemigracion.ucm.es/info/ especulo/numero33/pmbolano.html>. Acceso en: 23 may. 2016.

VILLACORTA GONZÁLEZ, C. Retrato del artista como un roedor: De Josefina la cantora o El pueblo de los ratones de Franz Kafka a El policía de las ratas de Roberto Bolaño. The Korean Journal of Hispanic Studies, v. 2, n. 6, p. 139-162, 2013.

WEBER, M. Economía y sociedad. México DF: Fondo de Cultura Económica, 2014.

Recibido: $11 / 12 / 2016$

Recebido: 11/12/2016

Aprobado: $14 / 01 / 2017$

Aprovado: 14/01/2017 